\title{
Optimization of Nutrient Medium for Pediococcus acidilactici DS15 to Produce GABA
}

\author{
Lili Anggraini ${ }^{1}$, Yetti Marlida ${ }^{2 *}$, Wizna Wizna ${ }^{2}$, Jamsari Jamsari ${ }^{3}$ and Mirzah Mirzah ${ }^{2}$ \\ ${ }^{I}$ Department of Agricultural Science, Faculty of Agriculture, Andalas University, 25163, Indonesia \\ ${ }^{2}$ Department of Animal Nutrition and Feed Technology, Faculty of Animal Science, Andalas University, 25163, Indonesia \\ ${ }^{3}$ Department of Crop Science, Faculty of Agriculture, Universitas Andalas, 25163, Indonesia \\ "Corresponding author’s Email: yettimarlida@ ansci.unand.ac.id; ORCID: 0000-0001-9134-3954
}

Received: 02 Aug. 2019

Accepted: 09 Sept. 2019

\begin{abstract}
Nutrition is an essential factor for microorganisms to grow and survive. Carbon and nitrogen sources are used in producing primary and secondary metabolites. Gamma-Aminobutyric acid (GABA), a non-coded amino acid, is a secondary metabolite which acts as an inhibitory neurotransmitter of the central nervous system. Pediococcus acidilactici DS15 is a bacterium belonging to the order of Lactic Acid Bacteria. This study aimed to determine the effects of nutrients including glutamate, nitrogen and carbon sources on GABA production by Pediococcus acidilactici DS15. The tests were carried out using a range of $30 \mathrm{mM}, 40 \mathrm{mM}, 50 \mathrm{mM}, 60 \mathrm{mM}$, and $70 \mathrm{mM}$ glutamate as inducer and carbon sources in the form of peptone, yeast extract, skim milk, $\mathrm{NH}_{4} \mathrm{NO}_{3}, \mathrm{KNO}_{3}$, whey tofu and soy milk as nitrogen sources, and then glucose, lactose, maltosa, sucrose, palm, and cane sugar as carbon sources. The best sources of both will be tested with levels 10, 20,30, 40, 50, 60, 70, 80, 90 and 100\% for nitrogen and 1, 3, 5, 7, $9,11,13$ and $15 \%$ for carbon. The results of this investigation revealed that the addition of $60 \mathrm{mM}$ glutamate caused the higher amount of GABA production and the best source of nitrogen and carbon for Pediococcus acidilactici DS15 were $100 \%$ whey tofu and $15 \%$ palm sugar, respectively. Production rate of GABA by Pediococcus acidilactici DS15 could reach up to $311,485 \mathrm{mg} / \mathrm{L}$.
\end{abstract}

Key words: Carbon, GABA, Glutamate, Nitrogen, Pediococcus acidilactici DS15

\section{INTRODUCTION}

Microorganisms are widely used in various industrial sectors. In the livestock fields, microorganisms are associated to health advantages and apply as probiotics and Direct-Fed Microbial (DFM) supplementations (Khan et al., 2016). In addition, they play important roles in feed ingredients processing such as fermentation, production of enzymes or other additive compounds. A short process, high production, and easy to use in the production process are some of the supporting factors for the use of microorganisms (Gurung et al, 2013).

The growth of microorganisms can be successful if nutritional, environmental and other requirements are properly provided. These available nutrients such as carbon and nitrogen in the growth medium will be used to produce primary and secondary metabolites (Thirumurugan et al., 2018). Primary metabolites are formed intracellularly and have an essential function for the survival of microbes, while secondary metabolites can be used as emergency nutrition to survive or to defend themselves in the final phase of growth or death phase (Thirumurugan et al., 2018).

Gamma-Aminobutyric Acid (GABA) is one of the secondary metabolites that can be used as an anti-stress agent for humans or livestock. GABA, a nonproteinogenic amino acid, acts as an inhibitory neurotransmitter of the central nervous system (CNS) (Murray et al, 2003). GABA dilates blood vessels and resulted in lowering blood pressure and are used as a medication for stroke treatment. Moreover, GABA has diuretics, tranquilizer, anti-oxidant, and pain relief effects and regulates the secretion of growth hormone (Hao and Schmit, 1993; Kono and Himeno, 2000; Leventhal et al., 2003).

It is demonstrated that GABA can be also produced by microorganisms such as bacteria, yeast and fungi 
(Dhakal et al., 2012). lactic acid bacteria (LAB) are considered as useful and safe microorganisms that are capable to produce GABA ( $\mathrm{Li} \mathrm{H}$ et al., 2010). Pediococcus acidilactici is a LAB which has been used as a starter culture in fermented meat, milk, and vegetable which causes distinctive taste changes, improves cleanliness and extends product shelf life (Mora et al., 1997; Porto et al., 2017). Pediococcus acidilactici have also been found in the process of production of traditional food such as dadih (fermented buffalo milk) (Anggraini et al., 2018).

Pediococcus acidilactici DS15 requires nitrogen and carbon to meet their daily needs both for living or producing GABA (Donnell et al., 2001; Savijoki et al., 2006). Most LAB strains usually prefer glucose as a carbon source (Kim et al., 2009). Glucose replacement with fructose, lactose, maltose, arabinose, and galactose can reduce GABA production (Cho et al., 2007). The use of inorganic or organic nitrogen can also affect the growth of LAB. Administration of inorganic nitrogen caused the growth of Lactobacillus buchneri WPZ001 to be severely inhibited, but providing organic nitrogen source leads to better growth of L. buchneri WPZ001 (Zhao et al., 2015). In addition to nitrogen and carbon nutrients, an inducer of glutamate is also needed to increase GABA production. Addition of exogenous glutamic acid can augment GABA synthesis (Kim et al., 2009). There is less data about nutritional requirements of Pediococcus acidilactici DS15 to produce GABA optimally. Therefore, the present study aimed to assess the different media nutrients in term of GABA production by Pediococcus acidilactici DS15.

\section{MATERIALS AND METHODS}

\section{Isolation of Pediococcus acidilactici DS15}

Pediococcus acidilactici DS15 was isolated from curds as LAB producing GABA (Anggraini et al., 2018). The bacteria were grown anaerobically at $30^{\circ} \mathrm{C}$ on MRS broth (Merck, Germany) and stored for further analysis. The experiment was carried out at the Feed Technology Industry Laboratory, Faculty of Animal Science, Andalas University, West Sumatra, Indonesia.

\section{GABA production medium}

The nutritional content of media in one liter consists of di-potassium hydrogen phosphate $2 \mathrm{gr}$, di-ammonium hydrogen citrate $2 \mathrm{gr}$, sodium acetate $5 \mathrm{gr}$, magnesium sulphate $0.2 \mathrm{gr}$, and manganese sulphate $0.02 \mathrm{gr}$.

\section{Optimization of source and nitrogen levels}

As nitrogen sources, GABA-producing LAB used peptone, yeast extract, skim milk, $\mathrm{NH} 4 \mathrm{NO} 3, \mathrm{KNO} 3$, whey tofu, and soy milk. The best results from nitrogen sources are continued with different levels of addition, namely 10 , $20,30,40,50,60,70,80,90$ and $100 \%$. The results were determined by calculating Optical Density (OD) using a spectrophotometer with a wavelength of $600 \mathrm{~nm}$. Then, GABA production was measured by centrifuging at a speed of 10,000 rpm, temperature $4^{\circ} \mathrm{C}$ and analyzed using Shimadzu HPLC (Kyoto, Japan) C18 column $(250 \mathrm{~mm} \times$ $4.6 \mathrm{~mm}$ I.D., particle size $5 \mu \mathrm{m} / \mathrm{L}$, Alltech, IL, USA)

\section{Optimization Source and Carbon Levels}

The treatment was repeated three times. As carbon sources, Pediococcus acidilactici used glucose, lactose, maltose, sucrose, granulated sugar, and palm sugar. The best results from carbon sources are continued with different addition levels, namely $1 \%, 3 \%, 5 \%, 7 \%, 9 \%$, $11 \%, 13 \%$ and $15 \%$. The results were determined by calculating OD using a spectrophotometer with a wavelength of $600 \mathrm{~nm}$. Then, GABA production was measured by centrifuging at a speed of $10,000 \mathrm{rpm}$, temperature $4^{\circ} \mathrm{C}$ and analyzed using Shimadzu HPLC (Kyoto, Japan) C18 column $(250 \mathrm{~mm} \times 4.6 \mathrm{~mm}$ I.D., particle size $5 \mu \mathrm{m} / \mathrm{L}$, Alltech, IL, USA).

\section{RESULTS AND DISCUSSION}

\section{Optimization of glutamate as an inducer}

The effect of giving glutamic acid as an inducer of GABA production and growth of Pediococcus acidilactici DS15 is shown in figure 1. Giving glutamic acid with a range of $0,2-1 \%$ did not seem to have much influence on growth, where the obtained OD value was $0.443 ; 0.459$; $0.453 ; 0.452$, and 0.445 . Whereas for the production of GABA there is a rise along with an increase in the concentration of glutamate acid given. The highest concentration of GABA was observed in the giving of inducer as much as $0,8 \%$, which was $159,047 \mathrm{mg} / \mathrm{L}$, but at the giving of $1 \%$, there was a slight decrease to 158,344 $\mathrm{mg} / \mathrm{L}$. Zhong et al. (2019) indicated that L-sodium glutamate at the concentration of $1 \%$ had the greatest capacity to enhance the production of GABA compared with the other concentrations by L. pentosus, However, the highest mycelium biomass was obtained with $\mathrm{L}$-sodium glutamate at $0.5 \%$.

In the present study, there is an increase in GABA production due to the increase in the amount of glutamate 
given that was consistent with the results of a previous study (Komatsuzaki et al., 2005). GABA is synthesized from glutamic acid with the help of Glutamic Acid Decarboxylase (GAD) (Kan et al., 2017) so that with the addition of glutamate, the GAD enzyme will be activated. Bibb (2005) declared that the synthesis of secondary metabolites was triggered by critical conditions of a nutrition or by adding of inducers to a growth medium. GABA synthesis is influenced by the ability of bacteria and also the presence of glutamate in the cell-matrix. The GAD enzyme in LAB is an intracellular enzyme (Huang et al., 2007; Komatsuzaki et al., 2008) that is synthesized as a form of a stress response to an acidic environment (Sanders et al., 1998; Small and Waterman, 1998). L- glutamate concentration can be increased by adding exogenous glutamate acid (Park and Oh, 2005; Seok et al., 2008; Kim et al., 2009; Zhuang et al., 2018), protease to hydrolyze proteins and produce glutamate acid, using LAB to hydrolyze proteins as co-cultures in the fermentation process (Inoue et al., 2003).

Figure 1 shows when the concentration of giving MSG exceed $0,8 \%$ resulting in decreased GABA production, therefore, there is an optimal limit of MSG as an inducer, which is $0,8 \%$. This finding is compatible with the study that has been reported excess monosodium glutamate can inhibit GABA production (Tung et al., 2011).

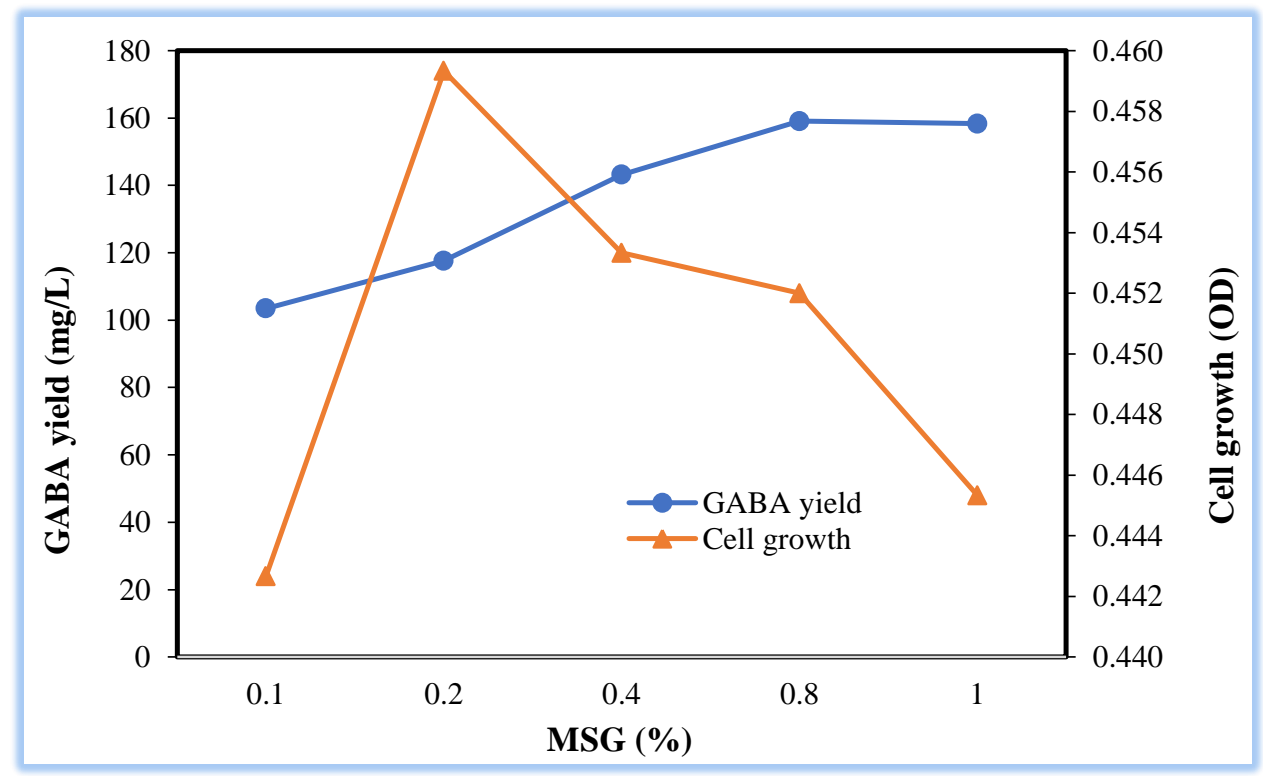

Figure 1. GABA production and growth curve of Pediococcus acidilactici DS15 based on glutamate dose

\section{Utilization of nitrogen sources}

The uses of various nitrogen sources were investigated to determine optimal GABA production. Figure 2 illustrates that the use of whey as a nitrogen source is breached compared to other nitrogen sources in producing GABA for Pediococcus acidilactici DS15; however, peptone was found as the best source of nitrogen in the growth of bacteria.

Figure 2 shows that the use of organic nitrogen sources (peptone, yeast extract, tofu water, and soy milk) increased GABA production and cell growth compared to inorganic nitrogen sources $\left(\mathrm{KNO}_{3}, \mathrm{NH}_{4} \mathrm{NO}_{3}\right.$, and urea). This result is in line with the research of Zhao et al. (2015) that reported the use of organic and inorganic nitrogen sources lead to a difference in the yield of GABA produced by $\mathrm{LAB}$. In the mentioned study, when a single inorganic nitrogen source such as urea, ammonium sulfate or citric acid diamine was given, the growth of L. buchneri WPZ001 was severely inhibited and the production of GABA reduced. But when peptone fish meal, meat extract, or stumped peptone were given singly, both cell growth and GABA production were higher.

Tofu liquid waste, also called whey tofu, is a byproduct in the process of tofu production. Whey tofu contains organic compounds such as organic nitrogen $(7.61 \%)$, total sugar $(0.32 \%)$, reducing sugars $(0.09 \%)$, and minerals (Ghofar et al. 2005). these organic compounds make whey an appropriate growth media for bacteria. The nutrient content of soybeans is what distinguishes whey tofu from commercial nitrogen sources including peptone, yeast extract, $\mathrm{NH}_{4} \mathrm{NO}_{3}$, and $\mathrm{KNO}_{3}$. 


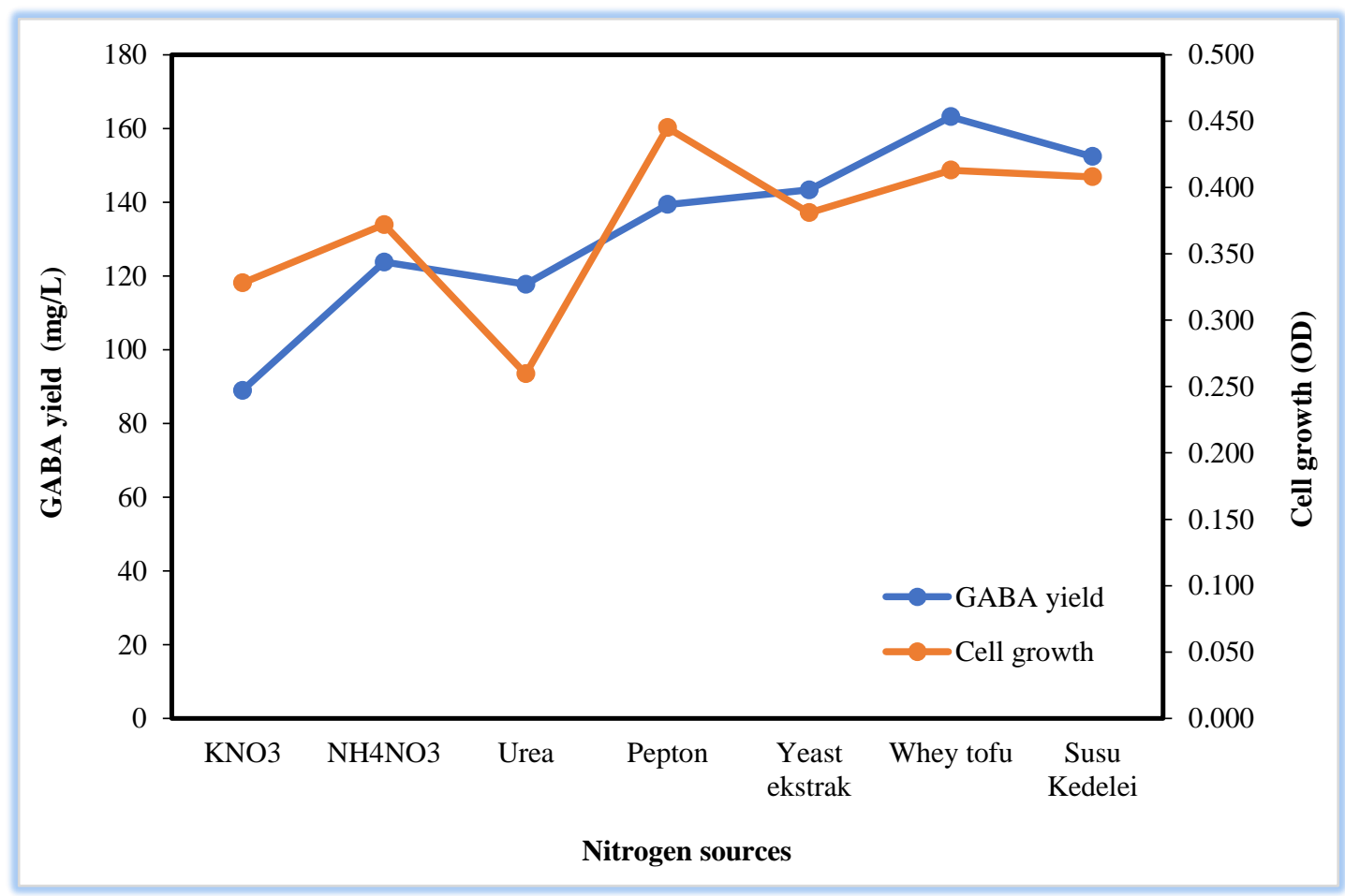

Figure 2. GABA production and growth curve of Pediococcus acidilactici DS15 in various nitrogen sources

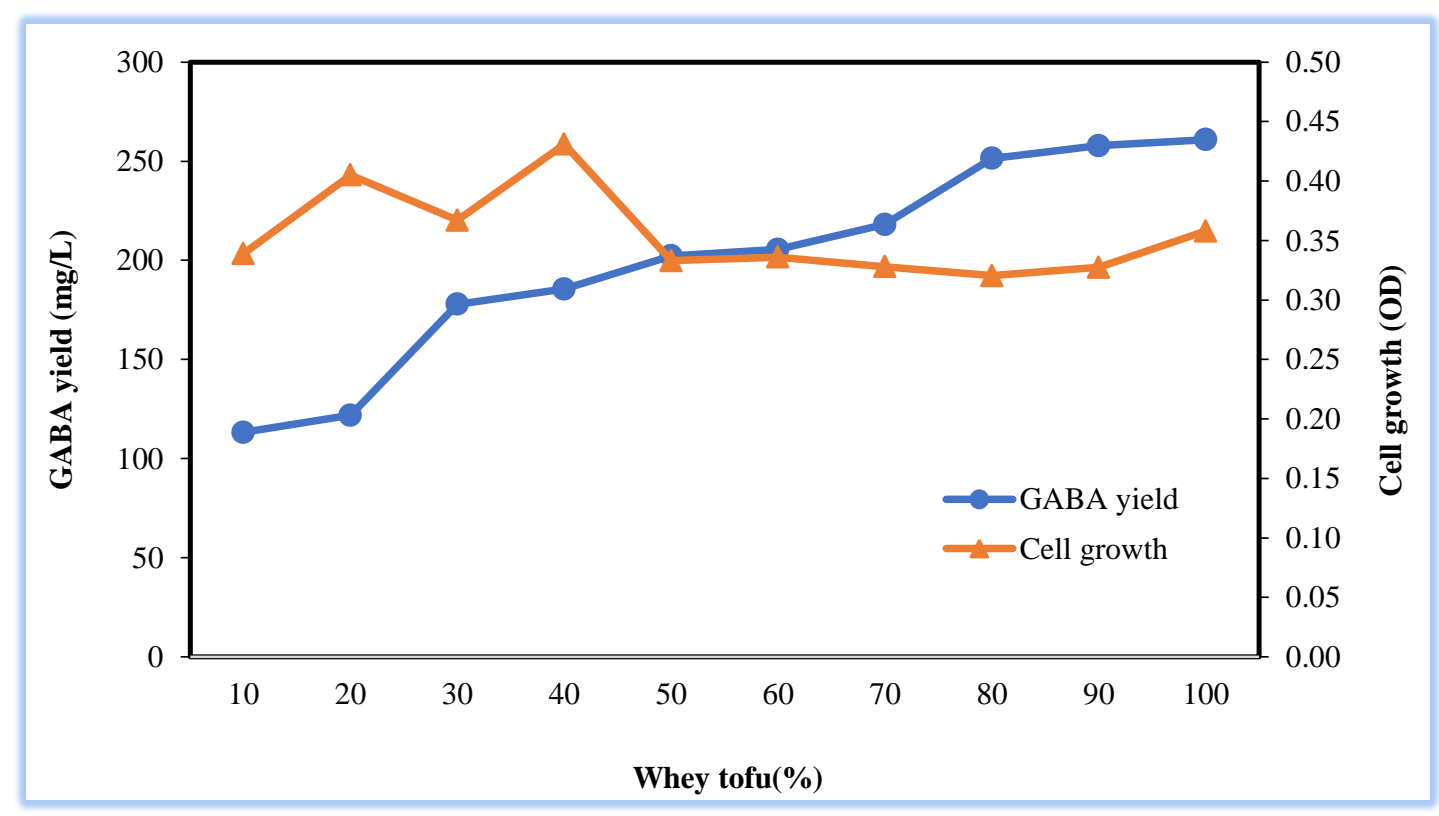

Figure 3. GABA production and growth curve of Pediococcus acidilactici DS15 based on the level of tofu liquid waste supply

\section{Level of use of tofu liquid waste}

The nitrogen source is used as a constituent material of cell biomass. LAB in the growth phase utilizes protein as a source of nitrogen, which is used by bacteria for protein synthesis, amino acids (Nisa et al., 2001). The highest cell growth was found in $40 \%$ of the use of whey tofu, and the use of more than $40 \%$ reduced cell growth (Figure 3). This decline is due to the high nitrogen content being the limiting factor for cells to grow. Changes in nutrient availability affect growth and biomass products (Leroy and de Vuyst, 2001). 
Figure 3 shows that GABA production increased with increasing dosage of whey tofu used. This is because higher the doses of whey tofu are richer in organic compounds such as organic nitrogen and minerals. According to the obtained results, it was found that $100 \%$ use from whey tofu could provide a good source of nitrogen for Pediococcus acidilactici DS15 to produce GABA.

\section{Utilization of carbon sources}

In the present study, several types of carbon sources in the form of simple sugars were used to determine the effects of type and amount of carbon sources on GABA production by Pediococcus acidilactici DS15.

Figure 4 illustrates that palm sugar is the best source of carbon compared to glucose, maltose, cane sugar, and sucrose which were used for the GABA production. In contrast to GABA production, the graph of cell growth of Pediococcus acidilactici DS15 showed that the highest cell growth was found in glucose as a carbon source, amounting to 0.419 , while the lowest was 0.378 in maltose. This difference can indicate that there is no correlation between the level of production of GABA and the number of bacterial cells.

The highest GABA production by Pediococcus acidilactici DS15 was $140.6 \mathrm{mg} / \mathrm{L}$ in utilizing palm sugar, followed by glucose, sugar cane, lactose, maltose, and sucrose with a production of 115,$774 ; 110.2 ; 109,554$; 94,284 and $79,813 \mathrm{mg} / \mathrm{L}$, respectively. In contrast to the study of Soe et al. (2013) which used Lactobacillus brevis to produce GABA, it was found that sucrose was the best source of carbon compared to fructose and maltose, which was $23.64 \mathrm{mM}$, while other studies reported that maltose is the best carbon source in GABA production by L.brevis K203 (Binh et al., 2014) and L.brevis HYE1 (Lim et al., 2017). In addition, xylose was described as the best carbon source L. buchneri WPZ001 to product GABA (Zhao et al., 2014). GABA production is affected by differences in the types and strains of LAB because each strain of LAB has differences in the use of carbon sources that can have impacts on growth and function of bacteria.

The cell growth of the Pediococcus acidilactici DS15 revealed differences in various carbon source. The highest growth is indicated by glucose, followed by sucrose, lactose, palm sugar, cane sugar and maltose. This difference in cell growth is caused by the type of sugar in each source. Palm sugar has a sugar content in the form of sucrose, which is a disaccharide composed by glucose and fructose, and a dextran which is a polysaccharide that has a chain of glucose branches. Glucose is usually a good source of carbon for bacterial growth but interferes with the formation of secondary metabolites (Demain, 1989). Papagianni and Sofia (2009) revealed that Pediococcus acidilactici can use sucrose as a carbon source. The culture medium contained a mixture of simple and complex carbon sources, the simple carbon source is used for cell formation and little or no secondary metabolites formation. Complex carbon sources will be used for idiolites formation after the simple carbon source has been used (Ruiz et al., 2010).

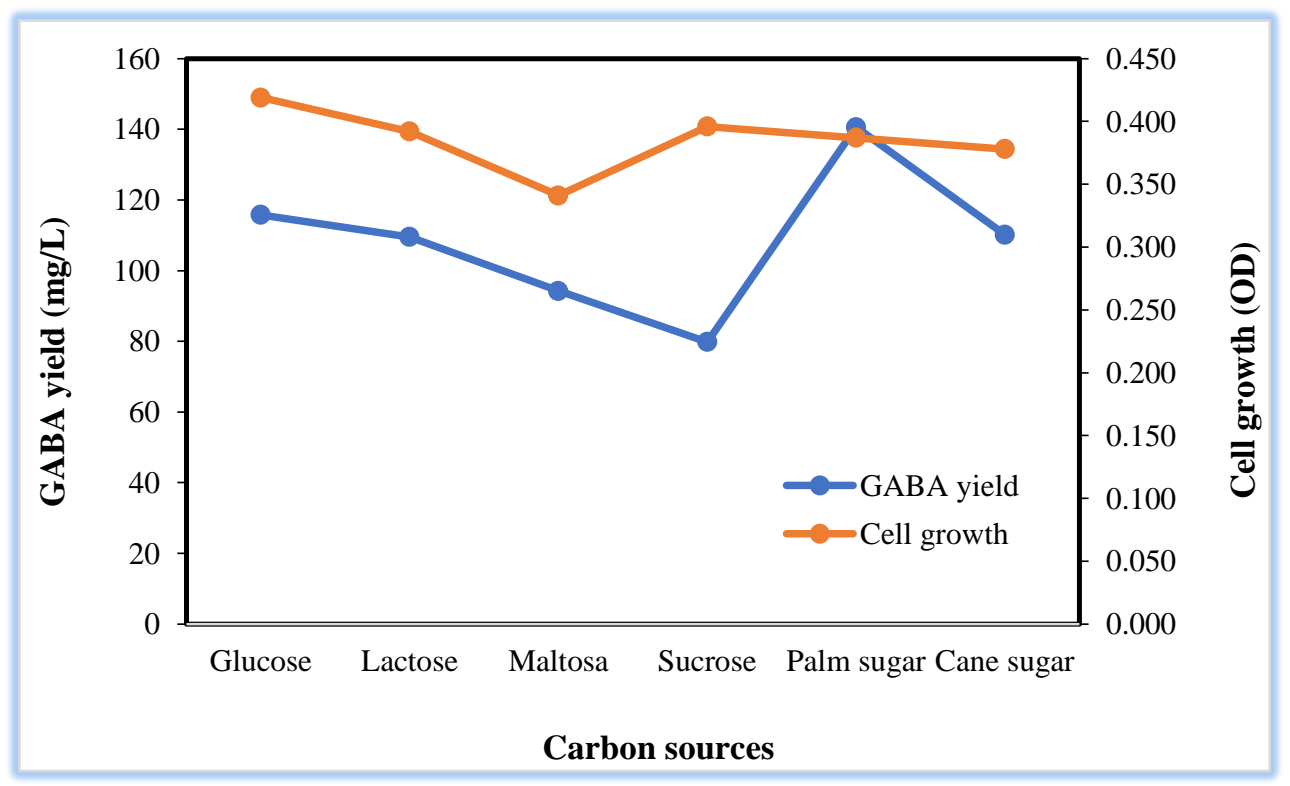

Figure 4. GABA production and growth curve of Pediococcus acidilactici DS15 in various carbon sources 


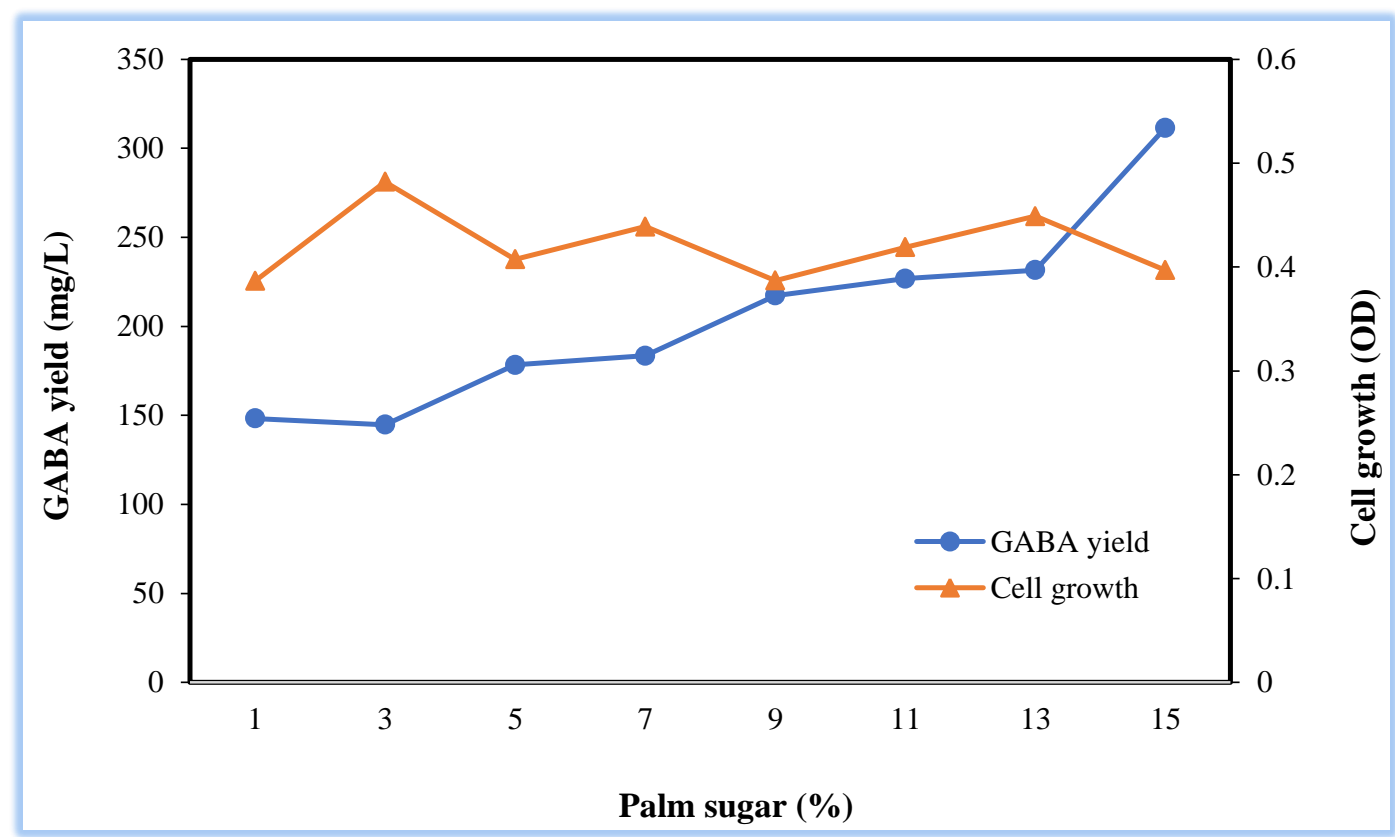

Figure 5. GABA production and growth curve of Pediococcus acidilactici DS15 based on the level of administration of palm sugar

\section{Level of use of palm sugar}

In the current study, the optimum dose of palm sugar as best carbon source were determined. According to the obtained results, it demonstrated that the production of GABA has increased along with the increase in the provision of palm sugar up to $15 \%$ by $311,485 \mathrm{mg} / \mathrm{L}$ (Figure 5). Previous studies have been reported that in order to GABA production, the best carbon sources to add to MRS media are 4\% sucrose for Lactobacillus sakei B216 (Kook et al., 2010), 3\% sucrose for L. brevis 340G (Soe et al., 2013), 1\% glucose for L.buchneri MS (Cho et al., 2007).

Palm sugar has high sucrose content which is used by Pediococcus acidilactici as an energy source. Addition of sucrose can increase the number of carbon sources as an energy source for cell growth so that the production of primary and secondary metabolites will increase.

The growth of microorganism including bacteria or fungi was strongly influenced by the presence of sufficient carbon sources, optimal temperatures, suitable $\mathrm{pH}$ conditions and other supporting conditions. Carbon sources that act as nutrients are needed for the survival of bacteria in producing primary metabolites as a necessity of life. If the nutrients contained in the media are overgrown in abundant amounts, then cell viability will increase

\section{CONCLUSION}

The best source of nitrogen and carbon in producing GABA by Pediococcus acidilactici DS15 were tofu water and palm sugar, respectively. The best concentration was $100 \%$ tofu liquid waste and $15 \%$ palm sugar resulted in production rate of GABA up to $311,485 \mathrm{mg} / \mathrm{L}$.

\section{DECLARATIONS}

\section{Acknowledgments}

We are very grateful to the Minister of Research, Technology and Higher Education of the Republic of Indonesia for funding this research through PMDSU No: 1387/E4./2015 and the support through World Class Professor Program Scheme-B No. 123.57/D2.3/KP/2018.

\section{Author's contribution}

Lili Anggrani and Yetti Marlida conducted the research, prepared data and wrote the article. Wizna, Jamsari and Mirzah cheked and confirmed the final form of article.

\section{Competing interests}

The authors declare that they have no competing interests. 


\section{Consent to publish}

All the authors gave their informed consent prior to their inclusion in the study.

\section{REFERENCES}

Ali Farrah WO, Nazamid Saari, Fatimah Abu B, AS Abdulamir, Abdulkarim Soba M, Yazid Abdul $M$ and Anwarul Hidayah Z (2009). Novel, practical and cheap source for isolating beneficial $\gamma$-aminobutyric acid-producing Leuconostoc NC5 bacteria. Research Journal of Medical Science, $\quad 3(4)$ : 146-153. http://medwelljournals.com/abstract/?doi=rjmsci.2009.14 6.153

Anggraini L, Marlida Y, Wizna W, Jamsari J, Mirzah M, Adzitey F and Huda N (2018). Molecular identification and phylogenetic analysis of GABA-producing lactic acid bacteria isolated from indigenous dadih of West Sumatera, Indonesia. F1000 Research, 7:1663. DOI: http://10.12688/f1000research.16224.2

Bibb MJ (2005). Regulation of secondary metabolism in streptomycetes. Current Opinion in Microbiology, 8:208215. DOI: http://10.1016/j.mib.2005.02.016

Binh TTT, Ju WT, Jung WJ and Park RD (2014). Optimization of $\gamma$-amino butyric acid production in a newly isolated Lactobacillus brevis. Biotechnology Letters, 36(1): 9398. DOI: http://10.1007/s10529-013-1326-Z

Cho YR, Chang JY and Chang HC (2007). Production of gamma aminobutyric acid (GABA) by Lactobacillus buchneri isolated from Kimchi and its neuroprotective effect on neuronal cells. Journal of Microbiology and Biotechnology, 17(1): 104-109. http://www.jmb.or.kr/journal/viewJournal.html?year=200 $7 \&$ vol $=17 \&$ num $=1 \&$ page $=104$

Dai SF, F Gao, WH Zhang, SX Song, XL Xu and GH Zhou (2011). Effects of dietary glutamine and gammaaminobutyric acid on performance, carcass characteristic and serum parameters in broiler under circular heat stress. Animal Feed Science and Technology, 168: 52-60. DOI: http://10.1016/j.anifeedsci.2011.03.005

Dai SF, F Gao, WH Zhang, SX Song, XL Xu and GH Zhou (2012). Effects of dietary glutamine and gammaaminobutyric acid on meat colour, $\mathrm{PH}$ composition, and water-holding characteristic in broilers under cyclic heat stress. British Poultry Science, 53 (4): 471-481. DOI: http://10.1080/00071668.2012.719148

Demain AL (1989). Carbon source regulation of idiolite biosynthesis. In: Regulation of secondary metabolism in Actinomycetes. Shapiro S Ed. Boca Raton, FL: CRC Press. 127-134.

Dhakal, Radhika, Vivek KB and Kwang HB (2012). Production of GABA ( $\gamma$ - Aminobutyric Acid) by microorganisms: A Review. Brazilian Journal of Microbiology, 43(4): 12301241. DOI: http://10.1590/S1517-83822012000400001

Ghofar A, Ogawa S and Kokugan T (2005). Production of Llactic acid from fresh cassava roots slurried with tofu liquid waste by Streptococcus bovis. Journal of Bioscience and Bioengineering, 100 (6): 606-612. DOI: http://10.1263/jbb.100.606
Gurung N, Ray S, Bose S and Rai V (2013). A broader view: Microbial enzymes and their relevance in industries, medicine, and beyond. BioMed Research International, 118. DOI: http://10.1155/2013/329121

Huang J, Mei L, Wu H and Lin D (2007). Biosynthesis of $\gamma$ aminobutyric acid (GABA) using immobilized whole cells of Lactobacillus brevis. World Journal of Microbiology and Biotechnology, 23: 865-871. DOI: http://10.1007/s11274-006-9311-5

Inoue K, Shirai T, Ochiai H, Kasao M, Hayakawa K, Kimura M and Sansawa H (2003). Blood-pressure-lowering effect of a novel fermented milk containing gamma-aminobutyric acid (GABA) in mild hypertensives. European Journal of Clinical Nutrition, 57:490-495. DOI: http://10.1038/sj.ejcn.1601555

Kan Chia-Cheng, Tsui-Yun C, Hsin-Yu W, Yan-An J and MingHsiun H (2017). Exogenous glutamate rapidly induces the expression of genes involved in metabolism and defense responses in rice roots. BMC genomics, 18:186. DOI: http://10.1186/s12864-017-3588-7

Khan Rifat Ullah, Shabana N, Kuldeep D, K Karthik, Ruchi T, Mutassim MA, Ibrahim AA and Arshad Z (2016). Directfed microbial: beneficial applications, modes of action and prospects as a safe tool for enhancing ruminant production and safeguarding health. International Journal of Pharmacology, 12 (3): 220-231. DOI: http://10.3923/ijp.2016.220.231

Kim JY, Geun EJ, Yeon SL and Keum TH (2009). Production of $\gamma$-aminobutyric acid in black raspberry juice during fermentation by Lactobacillus brevis GABA100. International Journal of Food Microbiology, 130: 12-16. DOI: http://10.1016/j.ijfoodmicro.2008.12.028

Komatsuzaki N, J Shima, S Kawamoto, H Momose and K Kimura (2005). Production of $\gamma$ amino butyric acid (GABA) by Lactobacillus paracasei isolated from traditional fermented foods. Food Microbiology, 22, 497 504. DOI: http://10.1016/j.fm.2005.01.002

Kook MC, Seo MJ, Cheigh CI, Pyun YR, Cho SC and Park H (2010). Enhanced production of gamma-aminobutyric acid using rice bran extracts by Lactobacillus sakei B216. Journal of Microbiology and Biotechnology, 20: 763 766. https://www.ncbi.nlm.nih.gov/pubmed/20467250

Leroy F and L de Vuyst (2001). Growth of the bacteriocinproducing Lactobacillus sakei strain CTC 494 in MRS broth is strongly reduced due to nutrient exhaustion: a nutrient depletion model for the growth of lactic acid bacteria. Applied and Environmental Microbiology, 67:4407-4413. DOI: http://10.1128/AEM.67.10.44074413.2001

Li H, Qiu T, Gao D and Cao Y (2010). Medium optimization for production of gamma-aminobutyric acid by Lactobacillus brevis NCL912. Amino Acids, 38:1439-1445. DOI: http://10.1007/s00726-009-0355-3

Lim Hee S, In-Tae C, Seong WR, Hae-Hun S and Myung-Ji S (2017). Enhanced production of gamma-aminobutyric acid by optimizing culture conditions of Lactobacillus brevis HYE1 isolated from Kimchi, a Korean Fermented Food. Journal of Microbiology and Biotechnology, 27(3), 450-459. DOI: http://10.4014/jmb.1610.10008 
Murray Robert K, Daryl K Granner, Peter A Mayes and Victor W Rodwell (2003). Harper's Illustrated Biochemistry. 23th edition. McGraw-Hill Companies, Inc. United Stated of America.

Papagianni Maria and Sofia Anastasiadou. (2009). Pediocins: The bacteriocins of Pediococci. Sources, production, properties and applications. Microbial Cell Factories, 8: 3. DOI: http://10.1186/1475-2859-8-3

Park KB and Oh SS (2005). Production and characterization of GABA rice yogurt. Food Science and Biotechnology, 14: (4) 518-522. https://www.researchgate.net/publication/299219041_Pro duction_and_characterization_of_GABA_rice_yogurt

Ruiz B, A Chávez, A Forero, Y García-Huante, A Romero, M Sánchez and E Langley (2010). Production of microbial secondary metabolites: Regulation by the carbon source. Critical Reviews in Microbiology, 36 (2): 146-167. DOI: http://10.3109/10408410903489576

Soe Myung-Ji, Ji-Yeon Lee, Young-Do Nam, So-Young Lee, SoLim Park, Sung-Hun Yi, Mi-Hwa Lee, Seong Woon Roh, Hak-Jong Choi and Seong-II Lim (2013). Production of $\gamma$-aminobutyric acid by Lactobacillus brevis $340 \mathrm{G}$ isolated from Kimchi and its application to skim milk. Food Engineering Progress, 17(4): 418-423. DOI: http://10.13050/foodengprog.2013.17.4.418

Seok JH, Park KB, Kim YH, Bae MO, Lee MK and Oh SH (2008). Production and characterization of Kimchi with enhanced levels of gamma-aminobutyric acid. Food and Agriculture Organization of the United Nations, 17: 940946.

https://www.researchgate.net/publication/289348612_Pro duction_and_characterization_of_Kimchi_with_enhanced _levels_of_g-aminobutyric_acid

Small PL and Waterman SR (1998). Acid stress, anaerobiosis and gadCB: lessons from Lactococcus lactis and
Escherechia coli. Trends in Microbiology, 6(6): 214-216. DOI: http://10.1016/S0966-842X(98)01285-2

Thirumurugana D, R Vijayakumarb, C Vadivalaganc, $\mathrm{P}$ Karthikad and Md KA Khan (2018). Isolation, structure elucidation and antibacterial activity of methyl-4,8dimethylundecanate from the marine actinobacterium Streptomyces albogriseolus ECR64. Microbial Pathogenesis, 121: 166-172. DOI: http://10.1016/j.micpath.2018.05.025

Tung Yi-Ting, Bao-Hong L, Chin-Feng $\mathrm{L}$ and Tzu-Ming $\mathrm{P}$ (2011). Optimization of culture condition for ACEI and GABA production by lactic acid bacteria. Journal of Food Science, 76: 585-591. DOI: http://10.1111/j.17503841.2011. 02379.x

Zhang H, Yao HY and Chen F (2006). Accumulation of gammaaminobutyric acid in rice germ using protease. Bioscience, Biotechnology and Biochemistry, 70: 11601165. DOI: http://10.1271/bbb.70.1160

Zhao A, Xiaoqing H, Lu P and Xiaoyuan W (2015). Isolation and characterization of a gamma-aminobutyric acid producing strain Lactobacillus buchneri WPZ001 that could efficiently utilize xylose and corncob hydrolysate. Applied Microbiology and Biothecnology, 99(7):3191200. DOI: http://10.1007/s00253-014-6294-2

Zhong Yangsheng, Shan W, Fangyan C, Mengxiu H and Jianrong L (2019). Isolation of high $\gamma^{-}$aminobutyric acidproducing lactic acid bacteria and fermentation in mulberry leaf powders. Experimental and Therapeutic Medicine, 18: 147-153. DOI: http://10.3892/etm.2019.7557

Zhuang Kejin, Yujun J, Xiaohan F, Li L, Fangfang D, Wei Z and Chaoxin M (2018). Transcriptomic response to GABAproducing Lactobacillus plantarum CGMCC 1.2437T induced by L-MSG. PLOS ONE, 13(6): e0199021. DOI: http://10.1371/journal.pone.0199021 